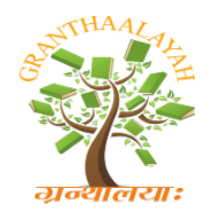

INTERNATIONAL JOURNAL OF RESEARCH GRANTHAALAYAH

A knowledge Repository

Social

\title{
IMPACT OF HYGIENE AWARENESS MODULE AMONG SELF HELP GROUP MEMBERS
}

\author{
Dr. Laxmi ${ }^{* 1}$ \\ ${ }^{* 1}$ Assistant Professor, Department of Social Work, Central University of Kerala, Kasargod, India
}

DOI: https://doi.org/10.29121/granthaalayah.v5.16.2017.2036

\begin{abstract}
Hygiene awareness plays an important role in preventing various communicable diseases like diarrhea. Intervention based researches should be conducted widely to address the issue of sanitation and hygiene. Self-help group members of rural area are focused as they are the best ambassadors in the villages to create awareness. Before the implementation of the module through workshop, pretest was conducted to assess their hygiene awareness. Later workshop was conducted and posttest was also done. A self-prepared interview schedule was used to collect data. It was found that there is significant difference in the pre and post test results. The knowledge and awareness of the respondents improved after the module implementation. All the respondents after the workshop mentioned that they would adopt better personal hygienic practices in order to promote a healthy life.
\end{abstract}

Keywords: Hygiene; Awareness; Module; Workshop; Impact; Pre Test; Post Test; Self Help Groups.

Cite This Article: Dr. Laxmi. (2017). IMPACT OF HYGIENE AWARENESS MODULE AMONG SELF HELP GROUP MEMBERS." International Journal of Research Granthaalayah, 5(6), 339-346. https://doi.org/10.29121/granthaalayah.v5.i6.2017.2036.

\section{Introduction}

For the purpose of this study, the term 'hygiene' is used to refer to the knowledge, behaviour and practices used to break the chain of infection transmission in the home and community. Hygiene education comprises a broad range of activities aimed at changing, knowledge, attitudes and behaviours. Hygiene education is an indispensable part of sanitation programmes and ensures improved health and sustainability. Kaviraj Motakpalli et al. (2013) conducted a study on "Health Hygiene among School Children in Rural Field Practice Area of AJIMS, Mangalore in Karnataka: India". It was found that out of 500 children examined, 63.4\% had good personal hygiene, $9.6 \%$ had fair personal hygiene, and $27 \%$ had poor personal hygiene. Out of the total, $31 \%$ of the children had Caries, $15 \%$ had fully blocked wax in the ear, $21 \%$ had coated tongue, and $11 \%$ had skin infections. This indicated the need for giving more stress on creating 
awareness about the importance of hygienic practices. Seenivasan et al. (2015) conducted a study to assess the knowledge, attitude, and practice of menstrual hygiene among rural women. The results of the study showed that $57.6 \%$ of the women were using napkins, $42.4 \%$ of the women were using cloth during menstruation, and $86.3 \%$ had knowledge of its proper disposal. Jain Akanksha et al. made a cross -sectional community based study titled "Menstrual Hygiene among Rural Unmarried Girls" in the village of Limbgaon, District Nanded, which is one of the training centres under the rural health training centre of Dr. Shankarrao Chavan Government Medical College, Nanded. It was found that $23.33 \%$ of the girls covered under the study used both soap and water for washing genitalia, while $60 \%$ of them used only water.

Self help groups (SHGs) are formed on a large scale in India, especially in rural areas. Large numbers of rural women have been enrolled into SHGs by both government and non government organizations with the aim to empower women. The objective of these groups is not only to lend money and savings, but also to focus on enhancing skills, knowledge, capacities, and awareness generation. SHGs act as vehicles of transformation. Various issues of the rural community can be tackled, if the members are properly trained and oriented. There is a wide need to assess the level of sanitation and hygiene awareness among the masses, and also to promote healthy sanitation and hygiene practices by using multiple strategies.

\section{Materials and Methods}

The study attempted to assess the hygiene awareness among the SHG women members. In the beginning stage, pre -test was conducted to assess the hygiene practices. After that, a workshop on 'Hygiene' was conducted to provide inputs in terms of knowledge and methods to sensitize about hygiene practices. Post-test was also conducted to assess the impact of the workshop with regard to knowledge and awareness to make the participants adopt better hygiene practices.

\subsection{Objectives}

- To assess the sanitation and hygiene practices among the respondents.

- To conduct a workshop that addresses the issues of awareness about sanitation and hygiene.

- To measure the impact of the workshop on 'hygiene awareness' among the SHG members.

\subsection{Methodology}

Experimental research design was adopted to measure the impact of hygiene module in bringing awareness.

\subsection{Universe}

The universe of the study was 18 SHGs formed in Kadkola village of Mysuru taluka and Mysuru district of Karnataka State by the Srinivasan Services Trust, CSR (Corporate Social Responsibility) wing of the TVS Motor Company, Mysuru. 


\subsection{Sampling}

Two members each randomly selected from 18 SHGs were requested to take part in the study making it a total of 36 members. As one of the members was absent, a total of 35 members formed the sample of the study. As the study was intervention- based using workshop module, a small size of the sample was decided.

\subsection{Inclusion and Exclusion}

- Only women self help group members were included in the study.

- Self help groups formed by TVS CSR wing were included in the study.

\subsection{Exclusion}

- Men self-help group members were not included in the study.

- Self-help groups formed by other agencies other than TVS CSR wing were not included in the study.

\subsection{Tools and Process of Data Collection}

A self- constructed structured interview schedule was developed to study various hygiene practices. Pre- and post- test was done to assess the sanitation and hygiene practices. A workshop was conducted to provide the input related to hygiene practices.

\section{Results and Discussion}

\subsection{Hygiene Practice}

Hygiene practices are employed as preventative measures to reduce the incidence and spreading of diseases. This particular section presents data on personal hygiene practices, water and hygiene, and food hygiene practices. Personal hygiene practices mainly focus on frequency of head bath in a week, face wash in a day, toothbrush in a day, hand wash before food, hand wash after defecation, and hand wash after cleaning vagina during menstruation.

Table 1: Personal Hygiene Practices Pre and Post- test

\begin{tabular}{|l|l|l|l|}
\hline \multicolumn{1}{|c|}{ Variables } & \multicolumn{1}{|c|}{ Classifications } & Pre-test (percentage) & Post-test (Percentage) \\
\hline \multirow{4}{*}{ Head bath in a week } & Once & $25.7(9)$ & 0 \\
\cline { 2 - 4 } & Twice & $31.4(11)$ & $31.4(11)$ \\
\cline { 2 - 4 } & Thrice & $34.3(12)$ & $60.0(21)$ \\
\cline { 2 - 4 } Face wash in a day & More than 3 times & $8.6(3)$ & $8.6(3)$ \\
\hline \multirow{3}{*}{ Toothbrush in a day } & Once & $8.6(3)$ & 0 \\
\cline { 2 - 4 } & Twice & $82.9(29)$ & $60.0(21)$ \\
\cline { 2 - 4 } & Three times & $8.6(2)$ & $40.0(14)$ \\
\hline Hand wash before food & Once & $51.4(18)$ & 0 \\
\cline { 2 - 4 } & Twice & $48.6(17)$ & $35(100)$ \\
\hline
\end{tabular}




\begin{tabular}{|l|l|l|l|}
\hline \multirow{4}{*}{ Hand wash after defecation } & Only water & $8.6(3)$ & 0 \\
\cline { 2 - 4 } & Other & $2.9(1)$ & 0 \\
\hline \multirow{3}{*}{$\begin{array}{l}\text { Hand wash after cleaning } \\
\text { vagina during menstruation }\end{array}$} & Soap and water & $91.4(32)$ & $100(35)$ \\
\cline { 2 - 4 } & Only water & $5.7(2)$ & 0 \\
\cline { 2 - 4 } & Other & $2.9(1)$ & 0 \\
\cline { 2 - 4 } & Soap and water & $77.1(27)$ & $100(35)$ \\
\cline { 2 - 4 } & Only water & $5.7(2)$ & 0 \\
\hline
\end{tabular}

Table 1 presents the pre- and post- test results of the hygiene practices of the respondents like frequency of head bath, face wash, and toothbrush and hand washing practices. In the pre- test, $25.7 \%$ used to take head bath once in a week, but in post- test no respondent wanted to take head bath once in a week; $31.4 \%$ of the respondents were taking head bath twice in a week during pretest and they wanted to continue the same practice; $34.3 \%$ of the respondents were taking head bath thrice in a week in the pre- test, and in post- test, $60 \%$ of the respondents were willing to take head bath three times in a week, and $8.6 \%$ of the respondents were taking head bath more than 3 times in a week in the pre- test and the same percentage of the respondents wanted to take head bath more than 3 times in a week. Frequent face wash in a day also contributes to the hygiene and health of a person. In the pre- test, $8.6 \%$ of the respondents were washing their face only once in a day and in post- test no one wanted to continue this; $82.9 \%$ of the respondents were washing their face twice in a day in pre- test, and in post- test, $60 \%$ wanted to wash their face twice in day, which means that $22.9 \%$ increased the number of face wash in a day and $8.6 \%$ of the respondents were washing their face three times in the pre- test, and in post- test, $40 \%$ wanted to face wash three times in a day. Oral hygiene is essential for the total health of an individual. Oral hygiene is the practice of keeping the mouth and teeth clean to prevent dental problems like dental cavities, gingivitis and bad breath. Brushing teeth twice in a day is required to maintain oral hygiene. In the study, $51.4 \%$ of the respondents were brushing their teeth only once in a day in the pre- test. But in the post- test, all the respondents want to brush twice in a day. With regard to hand washing practice, in the pre- test it was found that $88.6 \%$ used to wash their hands before eating food using soap and water. In post- test, all (100\%) the respondents told that they want to wash their hands using soap and water before eating food. About $91.4 \%$ of the respondents used to wash their hands using soap and water after defecation. In post- test all the (100\%) respondents want to wash their hands after defecation using soap and water. In the pretest, $77.1 \%$ of the respondents told that they will wash their hands after cleaning vagina during menstruation with soap and water. In post- test all the (100\%) respondents mentioned that they will wash their hands after cleaning vagina using soap and water. A study by Mayank Gupta, Sonia Tiwari, and Wavare (2015) found that, about 141(50.5\%) people in urban and 24 (33.8 $\%$ ) in rural areas used soap and water for cleaning of external genitalia.

From the above table, it is clear that there is a significant change in the attitude of the respondents with regard to hygiene practices after the implementation of the module. All the respondents after the workshop mentioned that they would adopt hygienic practices in order to promote a healthy life. Lack of proper information and sensitization is the cause for not adopting proper hygiene practices. People will change their attitude and practices if they are sensitized about the issues affecting them. 


\section{Hypothesis 1}

There is no significant difference between personal hygiene score at pre- and post- stages of self help group members.

\begin{tabular}{|l|l|l|l|}
\hline Sl. No. & \multicolumn{1}{c|}{ Items } & \multicolumn{2}{c|}{ Score } \\
\cline { 3 - 4 } & & \multicolumn{1}{c|}{ Yes } & \multicolumn{1}{c|}{ No } \\
\hline 1 & Do you bathe every day? & 1 & 0 \\
\hline 2 & Do you wash your hands before eating? & 1 & 0 \\
\hline 3 & Do you wash your plate before eating? & 1 & 0 \\
\hline 4 & Do you wash your hands after defecation? & 1 & 0 \\
\hline 5 & $\begin{array}{l}\text { Do you wash your hands after cleaning the vagina during } \\
\text { menstruation? }\end{array}$ & 1 & 0 \\
\hline \multicolumn{1}{|c|}{ Details of scoring } & $\begin{array}{l}\text { Highest } \\
5\end{array}$ & $\begin{array}{l}\text { Lowest } \\
0\end{array}$ \\
\hline
\end{tabular}

Testing-wise M, SD, N, and correlated t-value of personal hygiene

\begin{tabular}{|l|l|l|l|l|l|}
\hline Testing & Mean & Std. Deviation & Number of respondents & Correlated t-Test & Remark \\
\hline Pre-test & 4.31 & .758 & 35 & & $\begin{array}{l}\text { P }(.000) \\
<0.01 \\
\text { At df } 34\end{array}$ \\
\hline $\begin{array}{l}\text { Post- } \\
\text { test }\end{array}$ & 5.00 & .000 & 35 & 5.35 & \\
\hline
\end{tabular}

From the above information, it is evident that the co-related t-value is 5.35, which is significant at 0.01 level with $\mathrm{df}=34$. It indicates that the mean score of personal hygiene in the pre-test and post-test of the group differs significantly. Thus, the null hypothesis that there is no significant difference between personal hygiene score at pre and post stages of self help group members is rejected. Again, the mean score of personal hygiene after intervention in post-test is 5.00, which is significantly higher than the pre-test mean score, i.e., 4.31. It may, therefore be inferred that personal hygiene awareness among self help group members improved significantly through the treatment.

\subsection{Food and Hygiene}

\section{Hypothesis 2}

There is no significant difference between food related hygiene score at pre- and post- stages of self help group members.

\begin{tabular}{|c|c|c|c|}
\hline \multirow{2}{*}{ Sl. No. } & \multirow{2}{*}{ Statements } & \multicolumn{2}{|c|}{ Score } \\
\hline & & Agree & Disagree \\
\hline 1 & I wash the grains and grams before cooking. & 1 & 0 \\
\hline 2 & I wash the vegetables before chopping or cutting. & 1 & 0 \\
\hline 3 & I do not eat road side food. & 1 & 0 \\
\hline 4 & I take clean drinking water every time I go out. & 1 & 0 \\
\hline 5 & I wash the fruits before eating. & 1 & 0 \\
\hline 6 & I use clean water for cooking. & 1 & 0 \\
\hline 7 & I wash my hands before feeding the young children. & 1 & 0 \\
\hline
\end{tabular}




\begin{tabular}{|l|l|l|l|}
\hline 8 & I wash my hands before cooking. & 1 & 0 \\
\hline Details of scoring & $\begin{array}{l}\text { Highest score }= \\
8\end{array}$ & $\begin{array}{l}\text { Lowest } \\
\text { score }=0\end{array}$ \\
\hline
\end{tabular}

Testing-wise M, SD, N, and correlated t-value of food and hygiene

\begin{tabular}{|l|l|l|l|l|l|}
\hline Testing & Mean & Std. Deviation & $\begin{array}{c}\text { Number of umber of } \\
\text { respondents }\end{array}$ & Correlated t-Test & Remark \\
\hline Pre-test & 7.31 & .718 & $35 \quad 5.64$ & $\begin{array}{l}\text { P } \\
<0.01\end{array}$ \\
\hline $\begin{array}{l}\text { Post- } \\
\text { test }\end{array}$ & 8.00 & .000 & $35 \quad 000)$ & At df 34 \\
\hline
\end{tabular}

It is evident that the co-related t-value is 5.64 , which is significant at 0.01 level with $\mathrm{df}=34$. It indicates that the mean score of food hygiene in the pre-test and post- test differed significantly. Thus, the null hypothesis that there is no significant difference between food related hygiene score at pre and post stages of the self help group members is rejected. Again, the mean score of food hygiene after intervention in post-test is 8.00 , which is significantly higher than pretest mean score, i.e., 7.31. It may, therefore be inferred that food related hygiene awareness among self help group members improved significantly through the treatment.

Table 2: Water connectivity

\begin{tabular}{|l|l|l|l|l|l|}
\hline \multirow{2}{*}{ Main source of water } & \multicolumn{3}{|c|}{ Water connectivity (in percentage) } & \multirow{2}{*}{ Total } \\
\cline { 2 - 5 } & Not connected & $\begin{array}{c}4-7 \text { days in a } \\
\text { week }\end{array}$ & $\begin{array}{c}2-3 \text { days in a } \\
\text { week }\end{array}$ & $\begin{array}{c}\text { Once a } \\
\text { week }\end{array}$ & \\
\hline $\begin{array}{l}\text { Pipe water into } \\
\text { dwelling }\end{array}$ & 0 & $4.5(1)$ & $55.5(5)$ & $40(2)$ & $\mathbf{2 2 . 8 ( 8 )}$ \\
\hline Pipe water into yard & $10(2)$ & 0 & $45.5(4)$ & $60(3)$ & $\mathbf{2 5 . 7 ( 9 )}$ \\
\hline Public tap & $85(17)$ & 0 & 0 & 0 & $\mathbf{4 8 . 5}(\mathbf{1 7})$ \\
\hline Borewell & $5(1)$ & 0 & 0 & 0 & $\mathbf{2 . 8}(\mathbf{1})$ \\
\hline Total & $\mathbf{1 0 0 ( \mathbf { 2 0 } )}$ & $\mathbf{4 . 5 ( 1 )}$ & $\mathbf{1 0 0}(\mathbf{9})$ & $\mathbf{1 0 0}(\mathbf{5})$ & $\mathbf{1 0 0}(\mathbf{3 5})$ \\
\hline
\end{tabular}

The World Health Organization (2008) estimates that 50 percent of malnutrition is associated with repeated diarrhoea or intestinal worm infections from drinking unsafe water or poor sanitation or hygiene. Potable drinking water is crucial to prevent infection and diseases. Table 4.4 presents data on main water source and frequency of water supply. Majority (48.5\%) of the respondents use public tap, $25.7 \%$ have pipe water in their yard, $22.8 \%$ of the respondents have pipe water in their dwelling, and $2.8 \%$ use borewell water. About 20 out of 35 respondents do not have water connection, one has 4 to 7 days of supply of water, 9 have 2 to 3 days of supply, and 5 has once a week supply of water. 


\section{Hypothesis 3}

There is no significant difference between water related hygiene score at pre- and post- stages of self help group members.

\begin{tabular}{|l|l|l|l|}
\hline \multirow{2}{*}{ SI. No. } & \multicolumn{2}{c|}{ Items } & \multicolumn{2}{c|}{ Score } \\
\cline { 3 - 4 } & & 1 & \multicolumn{2}{c|}{ Yes } \\
\hline 1 & I treat the water before using it. & 1 & 0 \\
\hline 2 & I use storage container for drinking water. & 1 & 0 \\
\hline 3 & I use jug with handle to take water from the container. & 1 & 0 \\
\hline & Details of scoring & Highest $=3$ & Lowest $=0$ \\
\hline
\end{tabular}

Testing-wise M, SD, N, and correlated t-value of water related hygiene

\begin{tabular}{|c|c|c|c|c|c|}
\hline Testing & Mean & $\begin{array}{c}\text { Std. } \\
\text { Deviation } \\
\end{array}$ & $\begin{array}{c}\text { Number of umber of } \\
\text { respondents }\end{array}$ & $\begin{array}{c}\text { Correlated t- } \\
\text { Test } \\
\end{array}$ & Remark \\
\hline Pretest & 2.49 & .818 & 35 & \multirow[t]{2}{*}{3.17} & \multirow{2}{*}{$\begin{array}{l}\mathrm{P} \quad(.003) \\
<0.01 \\
\text { At df }=34\end{array}$} \\
\hline Posttest & 2.94 & .236 & 35 & & \\
\hline
\end{tabular}

It is evident that the co-related t-value is 3.17 , which is significant at 0.01 level with $\mathrm{df}=34$. It indicates that the mean score of water hygiene in the pre-test and post-test stages differs significantly. Thus, the null hypothesis that there is no significant difference between water related hygiene score at pre - and post - stages of self help group members is rejected. Again, the mean score of water hygiene after intervention in post - test is 2.94 , which is higher than the pre test mean score, i.e., 2.49. It may therefore be inferred that water related hygiene awareness among self help group members improved significantly through the treatment.

\section{Conclusion and Recommendations}

Awareness generation at various levels is very much essential to prevent infections and various communicable diseases. Community based organizations like self help groups are the effective platform to generate awareness especially in rural areas. It is evident from the study that there is significant difference in the knowledge and awareness of self help group members in pre and post test results. Interventions at micro level are imperative to create awareness among the masses. The study recommends following:

- Regular orientation, training, and workshops should be conducted in rural areas with regard to sanitation and hygiene focusing on self help groups (irrespective of gender) and school children.

- Multiple approaches like street plays, film shows, individual interaction, etc. should be used for communicating information.

\section{Acknowledgement}

My heartfelt thanks go to University Grants commission, New Delhi, for funding this project.

I also thank Pooja Bhagavath Memorial Mahajana Education Centre for providing mean opportunity to implement this project. 


\section{References}

[1] Gupta M., Tiwari S., Wavare R., R. (2015) “Awareness and Practices Regarding Menstrual Hygiene among Women of Reproductive Age Group Attending a Tertiary Care Hospital of Indore (M.P.)", National Journal of Community Medicine, Volume 6, Issue 2, ISSN 0976 3325 | eISSN 22296816 Apr - Jun.

[2] Jain Akanksha, Aswar N.R., Domple V.,K., Doibale Mohan K, Barure Balaji S. "Menstrual Hygiene awareness among Rural Unmarried Girls". Journal of Evolution of Medical and Dental Sciences 2014 ; Vol.3, Issue 06,February 10; Page: 1413-1419, DOI: 10.14260/jemds/2014/2000.

[3] Kaviraj Motakpalli, Amrutha Swati Indupalli, Siddesh Basavaraj Sirwar, Jayaalakshmi K.,N., Bendigeri N.D., and Deepak C., Jamadar (2013), "A Study on Health Hygiene Among School Children In Rural Field Practice Area of AJIMS, Mangalore In Karnataka: India”, International Journal of Bioassays, ISSN: 2278-778X.

[4] Seenivasan K., Caroline Priya, Arthi E., Gaviya.G., Kanchana Devi B., Karunya C., M,idhuna.G., Priyadharshini R., Priyadharshini S. (2015) A Cross Sectional Study on Awareness about Menstrual Hygiene among Rural Women, Stanly Medical Journal, Vol. 2, Issue. 2 Apri June.

*Corresponding author.

E-mail address: laxmi@cukerala.ac.in 